\title{
A Mash-up Authoring Tool for e-Learning based on Pedagogical Templates
}

\author{
Nicola Capuano, Anna Pierri \\ University of Salerno \\ Dept. of Information Engineering \\ and Applied Mathematics, Italy \\ +39089964189 \\ \{ncapuano@, pierri@diima.\} unisa.it
}

\author{
Francesco Colace \\ University of Salerno \\ Dept. of Information Engineering \\ and Electric Engineering, Italy \\ +39089964256 \\ fcolace@unisa.it
}

\author{
Matteo Gaeta, \\ Giuseppina Rita Mangione \\ CRMPA, Research Centre in Pure \\ and Applied Mathematics, Italy \\ +39089964374 \\ \{mangione, gaeta\} @crmpa.unisa.it
}

\begin{abstract}
The purpose of this paper is twofold. On the one hand it aims at presenting the "pedagogical template" methodology for the definition of didactic activities, through the aggregation of atomic learning entities on the basis of pre-defined schemas. On the other hand it proposes a Web-based authoring tool to build learning resources applying the defined methodology. The authoring tool is inspired by mashing-up principles and allows the combination of local learning entities with learning entities coming from external sources belonging to Web 2.0 like Wikipedia, Flickr, YouTube and SlideShare.

Eventually, the results of a small-scale experimentation, inside a University course, purposed both to define a pedagogical template for "virtual scientific experiments" and to build and deploy learning resources applying such template are presented.
\end{abstract}

\section{Categories and Subject Descriptors}

K.3.1 [Computer Uses in Education];

H.5.4 [Hypertext/Hypermedia].

\section{General Terms}

Design, Standardization, Experimentation.

\section{Keywords}

Learning Design, Mashup, Web 2.0.

\section{INTRODUCTION}

The research community on learning design recognizes that the pedagogical dimension of a learning experience is one of the most important elements to take into account in order to ensure a high sustainability level of e-learning [1]. To this objective the current challenge intends to provide teachers with proper technological proficiency and (on the other side) adequate tools to create a learning experience in which to demonstrate a good mastery of educational technology and learning experience design [2].

Permission to make digital or hard copies of all or part of this work for personal or classroom use is granted without fee provided that copies are not made or distributed for profit or commercial advantage and that copies bear this notice and the full citation on the first page. To copy otherwise, or republish, to post on servers or to redistribute to lists, requires prior specific permission and/or a fee.

$M T D L^{\prime} 09$, October 23, 2009, Beijing, China

Copyright 2009 ACM 978-1-60558-757-8/09/10 ...\$10.00
Suitable authoring tools enable educators to create engaging and interactive lessons that facilitate the learning with the integration of a myriad of multimedia contents. Unfortunately, many of the currently available tools are too complex to be used by the socalled "digital immigrant educators", subsequently a great number of scientific and learning associations are facing quite a critical point and also debates in the field are focused on who has really to use such tools: teachers or knowledge engineers.

The need for simpler e-learning authoring tools that could lower the skill barrier and allow more teachers to participate in the development and customization process is ever-increasing [3][4]. Moreover, to be really useful these tools should be able to reduce development time, effort, and cost, by allowing:

1. the reuse, enrichment and customization of available learning contents;

2. the emphasis on the pedagogical dimension of the defined learning experiences.

Toward such vision, we developed a design methodology (and a software tool) that expresses several types of didactic learning activities (e.g. reading, observing, interacting, testing) through the aggregation of atomic learning entities based on pre-defined but customizable schemas named "pedagogical templates".

The pedagogical templates, like design patterns in computer science [5], aim to provide a general reusable solution to reach a given set of didactic objectives in the context of a specific cognitive process (i.e. recall, understand, apply, analyse, evaluate, create). In section 2 we present in detail our methodology while in section 4 we compare our methodology with related works.

In order to implement and experiment pedagogical templates in real educational settings, we defined and developed an e-learning authoring tool that allows the definition of pedagogical templates and the combination of several kinds of digital objects (learning entities) on the basis of such templates.

The tool we developed is inspired by mashing-up principles allowing an easy and fast integration, over defined templates, of local and remote resources coming from Web 2.0 sources like Wikipedia, Flickr, YouTube and SlideShare. In section 3 we supply details on the developed prototype and in section 4 we compare it with some other existing e-learning editors.

On the basis of the developed prototype, an experimentation was conducted by real teachers and learners at the Faculty of Engineering of the University of Salerno. A "virtual scientific 
experiment template" based on four phases (presentation, practical situation, abstract situation, institutionalization) was defined and exploited to build complex learning objects. The results from the experimentation are presented in section 5. Section 6 concludes the work and presents future works planned on these topics.

\section{PEDAGOGICAL TEMPLATES AND COGNITIVE PROCESSES}

The process of creation of learning resources should outline and show explicitly the cognitive path that the teacher, as an author, is asked to follow with respect to pedagogical levels of didactic design. For this purpose, we suggest the adoption of design schemas for learning resources named pedagogical templates.

The pedagogical templates are directly connected to didactic activities. In order to obtain this connection rationally, we first identified some target cognitive processes and secondly linked them to activities which could maximize the objectives linked to the processes. In Table 1 we summarize a set of feasible elearning cognitive processes and link them to objectives.

Table 1. Mapping between cognitive processes, objectives and didactic activities.

\begin{tabular}{|l|l|l|}
\hline $\begin{array}{l}\text { Cognitive } \\
\text { Processes }\end{array}$ & Objectives & $\begin{array}{l}\text { Didactic } \\
\text { Activities }\end{array}$ \\
\hline Recall & recognize, remember & read, test \\
\hline Understand & $\begin{array}{l}\text { interpret, illustrate, classify, } \\
\text { summarize, infer, compare }\end{array}$ & $\begin{array}{l}\text { observe, } \\
\text { interact }\end{array}$ \\
\hline Apply & execute, implement & interact \\
\hline Analyse & $\begin{array}{l}\text { differentiate, organize, } \\
\text { impute }\end{array}$ & observe, test \\
\hline Evaluate & deepen, criticise & read \\
\hline Create & generate, produce & interact \\
\hline
\end{tabular}

Once we have identified "what" the teacher wants to achieve with respect to the learning objectives for each process, it is possible to go back to "how", by identifying specific categories of didactic activities and transforming them into templates.

Below, we list some macro-categories for identified activities and, for each of them, some defined templates.

1. Reading Activities: group learning resources adopting expressive forms that represent a concept or a content in form of text, tables, images. Templates in this category include: presentation, RSS feed, reading, reflection, introduction, image and text, glossary, Web site.

2. Observing Activities: group learning resources where learning happens through the passive observation of models, explanations and animations showing a sequence of activities or practical solution to a problem. Templates in this category include image gallery and simulation.

3. Interactive Activities: group learning resources where the user is invited to interact with the learning content including (guided) discovering activities. Templates in this category include drill \& practice, storytelling and case study.
4. Testing Activities: group learning resources purposed to learning evaluation and self-evaluation. Templates in this category include: true/false, multiple choice, drag \& drop, fill in blank, sort game, tile game, cloze activity, puzzle and matching.

Reasoning by pedagogical templates requires teachers to consider both design and development aspects. Concerning design aspects, the teacher has to confront with a set of information that lead him progressively to comprehension, necessary in choosing the activity. Such information concern the description of the activity, its didactic use, its planning and design.

Development aspects refer to the way the teacher has to manage the template within the authoring tool including workflow for template design, input form for template and connected metadata. Each template is defined with respect to design and development aspects. A selection of them is provided in tables 2 to 5 .

Table 2. Definition of the "presentation" template

\begin{tabular}{|l|l|}
\hline Aspect & Description \\
\hline $\begin{array}{l}\text { Activity } \\
\text { Description }\end{array}$ & $\begin{array}{l}\text { To follow a multimedia interactive } \\
\text { presentation on a given topic. }\end{array}$ \\
\hline Use & $\begin{array}{l}\text { To transfer declarative knowledge connected } \\
\text { with some concepts. }\end{array}$ \\
\hline $\begin{array}{l}\text { Planning ad } \\
\text { design }\end{array}$ & $\begin{array}{l}\text { To create a presentation (e.g. through } \\
\text { PowerPoint) and to transform it in a Web } \\
\text { object or to select a shared presentation on the } \\
\text { Web (e.g. on SlideShare). }\end{array}$ \\
\hline $\begin{array}{l}\text { Workflow for } \\
\text { template design }\end{array}$ & $\begin{array}{l}\text { To write the presentation introduction, to } \\
\text { specify a URL of a shared presentation or to } \\
\text { upload the presentation file, to specify tags and } \\
\text { metadata. }\end{array}$ \\
\hline $\begin{array}{l}\text { Input for the } \\
\text { template }\end{array}$ & $\begin{array}{l}\text { Some introductory texts and a URL (or a file } \\
\text { name). }\end{array}$ \\
\hline $\begin{array}{l}\text { Template } \\
\text { metadata }\end{array}$ & $\begin{array}{l}\text { Cognitive process name, activity category, } \\
\text { template name, presentation name, tags. }\end{array}$ \\
\hline
\end{tabular}

Table 3. Definition of the "reading" template

\begin{tabular}{|l|l|}
\hline Aspect & Description \\
\hline $\begin{array}{l}\text { Activity } \\
\text { Description }\end{array}$ & $\begin{array}{l}\text { To read a given textual document for the } \\
\text { knowledge acquisition on a given topic. }\end{array}$ \\
\hline Use & $\begin{array}{l}\text { To widen, deepen or clarify some specific } \\
\text { concepts by favouring critical analysis. To } \\
\text { assess retained knowledge (if linked to a report } \\
\text { to be written by the student). }\end{array}$ \\
\hline $\begin{array}{l}\text { Planning ad } \\
\text { design }\end{array}$ & $\begin{array}{l}\text { To create a document (e.g. through a word } \\
\text { processor) and transform it in a Web object or } \\
\text { to build a document directly on the Web (e.g. } \\
\text { through Google Docs) or to select an existing } \\
\text { feasible Web page (e.g. on Wikipedia) or to } \\
\text { collect a set of bibliographic references. }\end{array}$ \\
\hline $\begin{array}{l}\text { Workflow for } \\
\text { template design }\end{array}$ & $\begin{array}{l}\text { To write the reading introduction, to specify an } \\
\text { URL of a shared document or to upload the } \\
\text { document file, to specify tags and metadata. }\end{array}$ \\
\hline
\end{tabular}




\begin{tabular}{|l|l|}
\hline Aspect & Description \\
\hline $\begin{array}{l}\text { Input for the } \\
\text { template }\end{array}$ & $\begin{array}{l}\text { Some introductory texts and a URL (or a file } \\
\text { name). }\end{array}$ \\
\hline $\begin{array}{l}\text { Template } \\
\text { metadata }\end{array}$ & $\begin{array}{l}\text { Cognitive process name, activity category, } \\
\text { template name, document name, tags. }\end{array}$ \\
\hline
\end{tabular}

Table 4. Definition of the "image and text" template

\begin{tabular}{|l|l|}
\hline Aspect & Description \\
\hline $\begin{array}{l}\text { Activity } \\
\text { Description }\end{array}$ & $\begin{array}{l}\text { To associate a written text with an image } \\
\text { evoking the concept to be expressed. }\end{array}$ \\
\hline Use & $\begin{array}{l}\text { To describe a concept with the support of an } \\
\text { image. The image, by stimulating the brain's } \\
\text { left hemisphere, makes the learning simpler } \\
\text { and immediate, fosters intuition and speeds up } \\
\text { the building of cognitive links. }\end{array}$ \\
\hline $\begin{array}{l}\text { Planning ad } \\
\text { design }\end{array}$ & $\begin{array}{l}\text { To capture or create an image or to select it on } \\
\text { the Web (e.g. on Flickr or Fauxto). To write a } \\
\text { text, to include the image in it and to transform } \\
\text { all in a Web object. }\end{array}$ \\
\hline $\begin{array}{l}\text { Workflow for } \\
\text { template design }\end{array}$ & $\begin{array}{l}\text { To specify a URL of a shared image or to } \\
\text { upload the image file, to write the related text, } \\
\text { to specify tags and metadata. }\end{array}$ \\
\hline $\begin{array}{l}\text { Input for the } \\
\text { template }\end{array}$ & $\begin{array}{l}\text { A URL (or a file name) for the image and the } \\
\text { related text. }\end{array}$ \\
\hline $\begin{array}{l}\text { Template } \\
\text { metadata }\end{array}$ & $\begin{array}{l}\text { Cognitive process name, activity category, } \\
\text { template name, image name, tags. }\end{array}$ \\
\hline
\end{tabular}

Table 5. Definition of the "simulation" template

\begin{tabular}{|l|l|}
\hline Aspect & Description \\
\hline $\begin{array}{l}\text { Activity } \\
\text { Description }\end{array}$ & $\begin{array}{l}\text { To follow an interactive video simulation on a } \\
\text { given topic. }\end{array}$ \\
\hline Use & $\begin{array}{l}\text { To transfer procedural knowledge showing } \\
\text { operations needed to perform a given task. }\end{array}$ \\
\hline $\begin{array}{l}\text { Planning ad } \\
\text { design }\end{array}$ & $\begin{array}{l}\text { To capture or create a video or a screen-cast } \\
\text { with feasible devices and/or video editing } \\
\text { software and transform it in a Web object or to } \\
\text { select a shared video or animation on the Web } \\
\text { (e.g. on YouTube or Toufee). }\end{array}$ \\
\hline $\begin{array}{l}\text { Workflow for } \\
\text { template design }\end{array}$ & $\begin{array}{l}\text { To write the simulation introduction, to specify } \\
\text { a URL of a shared video or to upload the video } \\
\text { file, to specify tags and metadata. }\end{array}$ \\
\hline $\begin{array}{l}\text { Input for the } \\
\text { template }\end{array}$ & $\begin{array}{l}\text { Some introductory texts and a URL (or a file } \\
\text { name) }\end{array}$ \\
\hline $\begin{array}{l}\text { Template } \\
\text { metadata }\end{array}$ & $\begin{array}{l}\text { Cognitive process name, activity category, } \\
\text { template name, video or animation name, tags. }\end{array}$ \\
\hline
\end{tabular}

Once defined or selected the suitable pedagogical template, in order to build a learning resource, it is necessary to instantiate the template by linking it to learning entities. With learning entity we mean any atomic digital object that can be used in a learning process alone or in combination with other learning entities.
Example of learning entities are documents, presentations, Web pages, definitions, images, videos, screen casts, wikis, blogs, etc. The process of construction of learning resources, starting from learning entities, is depicted in Figure 1.

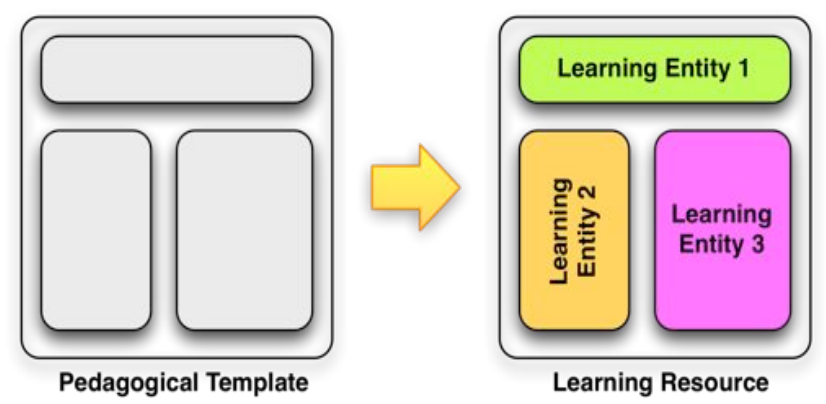

Figure 1.The process of learning resource building.

As already introduced, the learning entities may be created directly by teachers using feasible multimedia devices and authoring tools or selected from external sources. The Table 6 lists some types of learning entities, feasible Web 2.0 sources for such entities and learning resources where they can be exploited in. As reported in the next section, our prototype is able to deal with a subset of such entities.

Table 6. Learning entities and Web 2.0 Source

\begin{tabular}{|l|l|l|}
\hline Learning Entity & Web 2.0 Source & Learning Resource \\
\hline Definitions & Wiktionary & Glossary \\
\hline Documents & Google Docs & Reading, introduction \\
\hline $\begin{array}{l}\text { Encyclopedic } \\
\text { definitions }\end{array}$ & Wikipedia & $\begin{array}{l}\text { Reading, introduction, } \\
\text { Web site }\end{array}$ \\
\hline Images & Flickr, Fauxto & $\begin{array}{l}\text { Image and text, } \\
\text { reflection, image } \\
\text { gallery }\end{array}$ \\
\hline $\begin{array}{l}\text { Interactive } \\
\text { animations }\end{array}$ & Toufee & $\begin{array}{l}\text { Simulation, drill \& } \\
\text { practice }\end{array}$ \\
\hline Presentations & SlideShare & Presentation, reading \\
\hline Video clips & $\begin{array}{l}\text { YouTube, } \\
\text { Ustream }\end{array}$ & $\begin{array}{l}\text { Simulation, case } \\
\text { study, storytelling }\end{array}$ \\
\hline Wiki & Wikia & $\begin{array}{l}\text { Reflection, Web site, } \\
\text { storytelling }\end{array}$ \\
\hline
\end{tabular}

Moreover templates and learning entities are also classified through a tagging mechanism that takes into account both local tags and tags from external Web 2.0 sources. The use of this mechanism allows to surf the learning entity space with a tag cloud where tag width is congruent to tag importance. 
Moreover tagging allows the users to search learning entities and templates by crossing information from different sources (internal and external) and users (the insertion of a new entity or template with a specific tag makes these objects visible by users who have used the same tag).

\section{THE IMPLEMENTED PROTOTYPE}

In order to experiment pedagogical templates in real settings, we developed a Web-based authoring tool capable of building learning resources through the composition and the enrichment of atomic learning entities available on Web 2.0 sources. Among the lists presented in the previous section, different kinds of learning entities can be defined and used by our prototype, such as:

- encyclopedic definitions (selected from Wikipedia),

- $\quad$ image files (selected from Flickr),

- $\quad$ video clips (selected from YouTube),

- multimedia presentations (selected from SlideShare),

- $\quad$ editable hypertext (user-made HTML fragments),

- documents (user-made multimedia files),

- actions (commands for learning object navigation).

Learning entities may be combined together in order to obtain learning resources. Learning resources may span a single page or multiple pages and may be done "from scratch" or starting from a given pedagogical template.

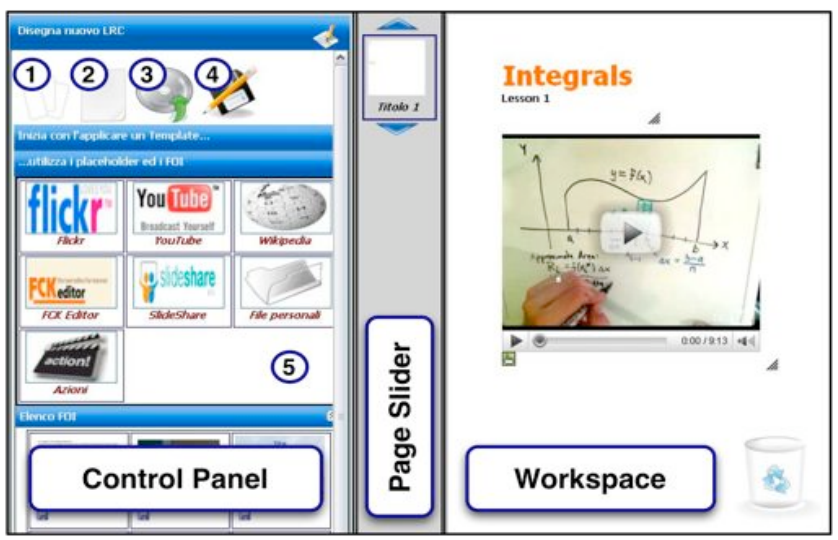

Figure 2. Prototype user interface.

Figure 2 shows the prototype user interface. It is composed of two main sections: the control panel that includes all available functions and the workspace that provides a visual representation of the resulting learning resource. A page slider is also provided in the middle to deal with multi-page resources.

From the control panel it is possible to load an existing learning resource or to start with a new one. In both cases the following editing commands appear (numbers refer to captions in figure 2):

1. add a new page to the current learning resource;

2. clean the current workspace;

3. upload a new document from the user local drive;

4. save the current learning resource;

5. add a new learning entity (of any kind).
Icons representing learning entity types can be dragged from the control panel and dropped in the workspace. Once dropped they become placeholders for learning activities and may be moved, resized and deleted (by putting them into the basket at the bottomright corner of the workspace).

Figure 3 represents a sample workspace configuration made of several placeholders. An editable hypertext (1) is placed on the top to provide a title and a subtitle. Under that an image file (2) and another editable hypertext (3) are placed to provide a description of the resource objectives. The placeholder for a multimedia presentation (4), learning resource core, is placed at the bottom.

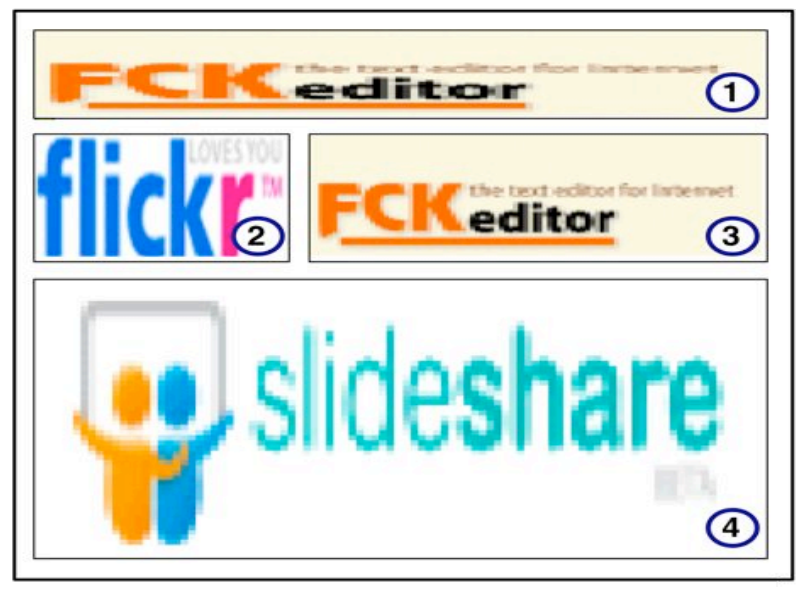

Figure 3. Sample pedagogical template.

Such configuration may be saved as a pedagogical template and used as a basis for the development of future learning resources (in such sense a pedagogical template can be seen as an abstract learning resource composed of placeholders for learning entities). Otherwise a learning resource may be created by directly binding learning entities to placeholders.

The learning entities can be selected in the system repository or on external Web 2.0 sources through a search panel (see figure 4). Users can start a new search by entering a list of keywords and by specifying the search target (1). Search results are presented as thumbnails and may be browsed through a pager (2).

Remote learning entities may be stored in the system repository (3). In such a case a name, a description and a set of tags may be associated (default values are obtained from Web sources). Stored entities may be modified (4) or deleted (5). Both stored or remote entities may be bound to placeholders through the drag \& drop.

The binding process works in two different ways: the stored entities are statically bound to the learning resource (i.e. they become part of the resource) while the remote entities are dynamically bound to it (i.e. they are included on-the-fly in the learning resource when loaded in the Web browser).

The editable hypertexts are slightly different from other learning resources. First of all they don't refer to external sources and can be searched only in the system repository (if previously saved) or directly edited through a Web-based HTML editor. Moreover, they can be used to modify or enrich external learning entities by simply dragging such entities from the search panel and dropping them in an editable hypertext placeholder. 


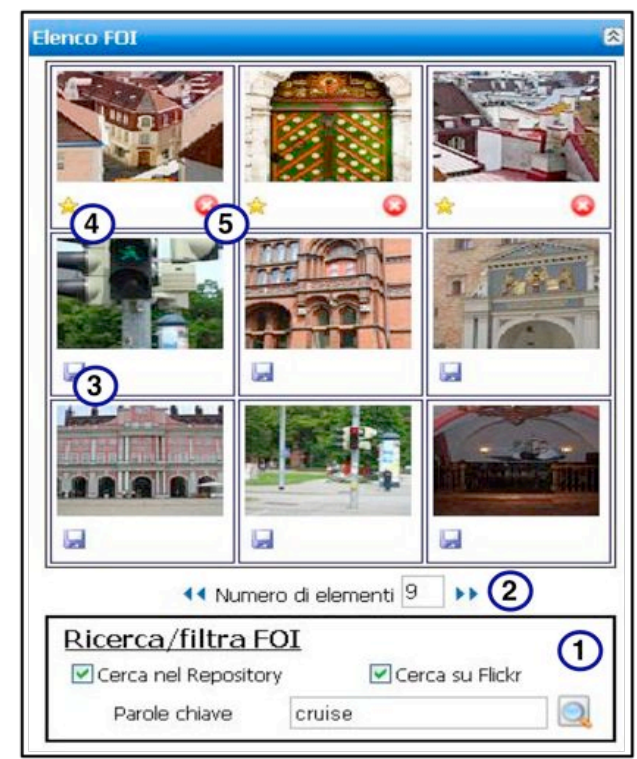

Figure 4. The search panel.

Once modified, such entities are bound on the learning resource and may be saved in the repository as any other hypertext, and reused to build further learning resources. As an example, figure 5 shows a sample learning resource composed of a video clip, an image file and an editable hypertext defined on the basis of an existing encyclopedic definition taken from Wikipedia.

The system is developed in ASP.NET and exploits ASP.NET AJAX and Yahoo! User Interface libraries to provide a rich and fully interactive user's experience. The application is deployed on a Microsoft IIS server and uses Microsoft SQL Server as a database management system. Integration with external Web 2.0 sources (Flickr, YouTube, Wikipedia and SlideShare) is made through APIs mainly relying on Web Services and RSS feeds.
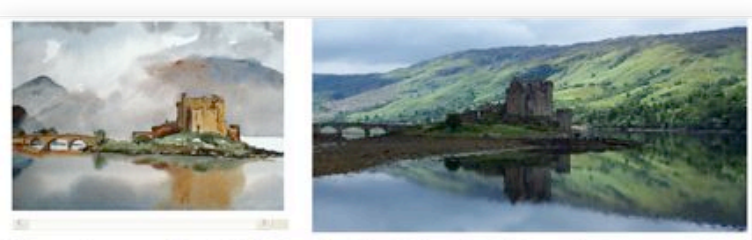

Eilean Donan (Scottish Gaelic for Island of Donan), is a small island in Loch Duich in the western Highlands of Scotland. It is connected to the mainland by a footbridge and lies about half a mile from the village of Dornie. Eilean Donan is named after St. Donan, a celtic saint martyred in the Dark Ages.

Eilean Donan castle

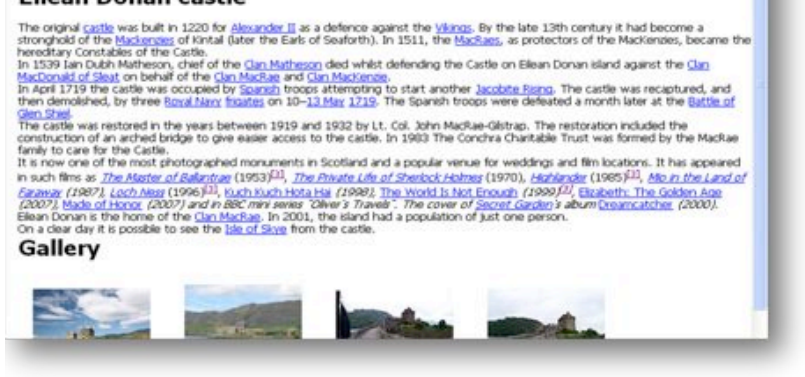

Figure 5. Sample output of a learning resource.

\section{COMPARISONS WITH RELATED WORKS}

The concept of pedagogical template (in some cases named as "pedagogical pattern") is not new and generally indicates the pedagogical transposition of design patterns.

The pedagogical templates are used to capture and communicate recurrent instructional design problems and opportunities. "Each pattern describes a problem occurring over and over and the core solution to that problem" [7]. They can be applied to instructional designs at two different levels:

1. for learning materials and multimedia production, such as defining patterns for learning management systems (i.e. a subset of Web design patterns [8]);

2. for instructional activities of different scale, from the organization of a whole course to the definition of very specific learning activities [9].

In [10] the pedagogical templates are defined as "models showing how technology can be integrated in teaching and learning activities". With this meaning, the templates can span distance and blended learning and can include online administrative support, follow up, parallel blended learning, face-to-face events, online distance support, online resource based and online discussion based learning.

In [11] the pedagogical patterns are used to offer a broader framework to assist the instructor with the development and delivery of a successful and engaging learning experience and implying a sound educational foundation.

Within the "pedagogical pattern" project [12] several patterns to solve common learning problems are defined in a formal way and systematically classified. A method to search and retrieve them by querying a specific learning goal definition is also provided.

Although our vision about the pedagogical templates takes inspiration from these works, its scope is narrower being it mainly purposed to facilitate the learning design of very fine-grained activities in an e-learning context, that places teaching and learning at the centre of the design process. Our vision as well fosters the process of design and refinement of the pedagogical templates.

To support the pedagogical templates we also defined and developed an innovative learning authoring tool based on aggregation technologies and allowing the definition of learning resources through the combination and enrichment of learning entities. There are several third-party authoring tools working in a similar way.

Among the others eXe Learning [13] is an open source Web based authoring environment conceived to assist the teacher with the design, development and publishing of Web-based learning resources, without requiring specific competencies related to authoring and editing or any need for HTML or XML language proficiency standards.

eXe is the result of a New Zeland's project dating 2004 aiming at fostering excellence in Education in tertiary sector. Just like our prototype, eXe allows the users to exploit a sort of template, called iDevices, for the content creation and reuse. Available eXe iDevices include: activity, case study, text, image gallery, question (several kinds available), objectives, RSS, reading activity, reflection, quiz, wiki article. 
Differently from the pedagogical templates, iDevices are provided as they are and can't be neither modified by users nor created from scratch without programming expertise. So while eXe uses pre-defined iDevices as building blocks for learning experiences, our prototype allows the users to design, create and modify pedagogical templates according to their specific needs.

Moreover, eXe does allow the users to link some external resources like Web pages, images or videos (presentations are not directly supported) but differently from our prototype, doesn't allow to browse and search external Web 2.0 sources directly inside the editor interface (i.e. no integration with Web 2.0 applications APIs is provided).

Another learning editor based on templates only recently released by Microsoft is the Learning Content Development System (LCDS) [14]. LCDS is conceived for the design and development of didactic interactive components structured as courses, units, lessons and topics. The creation of content, at each level, is managed through the modification of a set of pedagogical templates which simulate specific didactic activities.

LCDS includes five template categories: read, watch, interact, play and try, each one containing a few selection of templates that can be picked and composed to build new learning resources. Available templates include interactive activities, games, animations, demos, quizzes and competency assessment. The template library is continuously increasing.

As eXe, also the LCDS templates are provided as they are and can't be modified at all, moreover no custom templates are supported. Concerning the integration of learning entities from external sources, there are no templates available for this purpose. Both these aspects can be considered as limitations with respect to our approach.

Apart from the support given by customizable templates and the capability to combine external sources better than the existing tools are able to do, our tool gives another advantage in that it applies a mash-up approach so that a learning resource can be composed easily and quickly combining information and functions from external sources [15].

In this perspective our tool uses open APIs provided by external Web 2.0 sources (i.e. Wikipedia, Flickr, YouTube and SlideShare) to produce results that were not the original reason for us to produce such a raw source data. Differently from available authoring tools which are based on the portal technology, the content aggregation takes place directly on the client rather than the server-side by applying a variation of the well-known facade design pattern [5].

Moreover, the aggregation style selected in our tool follows a melting-pop style, namely the learning entities may be combined in different ways basing on the templates, and results in arbitrarily structured hybrid contents. This is in contrast with the salad bar style applied by similar tools where content is presented side-byside without any overlaps. It therefore gives teachers more degree of freedom for the definition of their learning resources.

For these reasons, our prototype can be also compared to the available mash-up editors like Microsoft Popfly [16], Mozilla Ubiquity [17] and Yahoo Pipes [18]. With respect to such tools, our editor allows the creation of simple mash-ups (e.g. we do not offer any support for Web service chaining) specifically targeted for e-learning and based on the pedagogic template methodology here defined (guided by the pedagogic approach).

\section{EXPERIMENTATION}

On the basis of the prototype developed, an experimentation was carried out involving teachers and learners of a Mathematics Course at the Faculty of Engineering of the University of Salerno. It was mainly purposed to validate both the prototype and the underlying methodology. For this reason no quantitative data has been collected yet.

The teachers involved in the experimentation had to create a complex pedagogical template for a Virtual Scientific Experiment (VSE) through the extension of the simulation template and basing on an already defined formal activity model [19]. According to the arranged template they were asked to build some sample learning resources, having the possibility to also rely on external learning entities from Web 2.0 sources.

As depicted in Figure 6, the VSE activity model is composed of a sequence of four macro-phases (presentation, practical situation, abstract situation and institutionalization), all comprising various micro-phases (e.g. active involvement, collaborative learning, assessment and addressed situation).

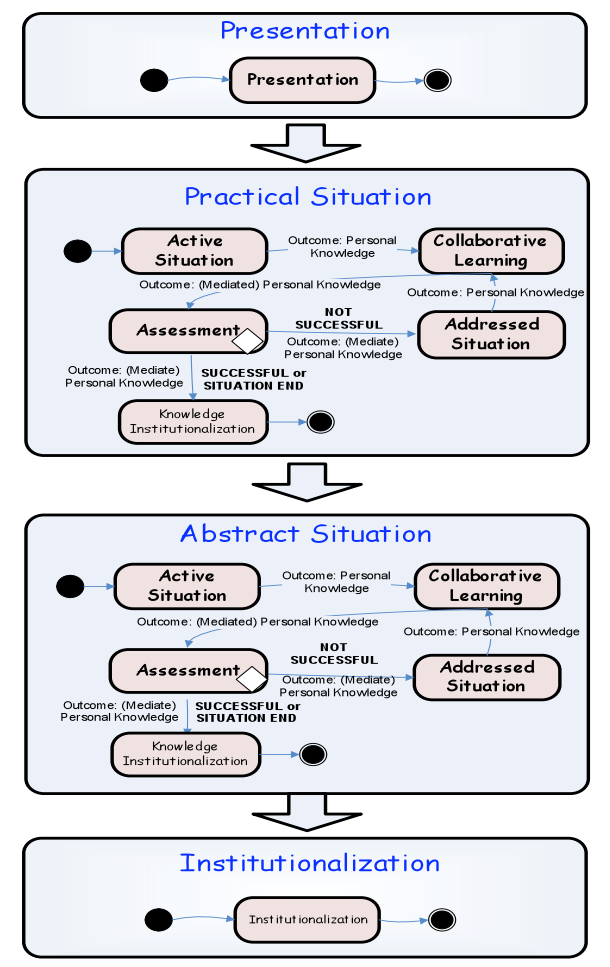

Figure 6. The VSE activity model

The phase of Presentation provides a description of the didactic experience that the student is about to start. To such aim, some preliminary indications are provided like the description of VSE phases, the available learning entities the learner will interact with and a description of the underlying concepts.

The Practical Situation represents the phase in which the learner lives the concrete experience that is under examination. The micro-phases characterizing this phase are therefore simulation and presence of a collaborative environment in which the concrete 
and personal learners' experience could be mediated through the interaction with others learners.

In the Abstract Situation we extrapolate an abstract model from the context previously analyzed i.e. we set-up the activities executed in each phase at an advanced level of abstraction.

The Institutionalization constitutes a passage from intuitive knowledge and spontaneous concepts to evolved forms of thought organization. The intuitive knowledge is firstly extracted from the analysis of a practical situation and, subsequently, from the abstract situation. At the end of the process, the knowledge is reorganized and formalized on the basis of principles and logical laws.

Starting from the abstract activity model, a template is designed by exploiting four pages (one for each macro-phase) and using action learning entities to move between pages.

- $\quad$ Page 1 (figure 7a) is composed of an editable hypertext providing a title and a description for the VSE and a button command to go to the next page. This page shows VSE purposes, involved parameters and some additional information.

- $\quad$ Page 2 (figure 7b) is composed of an editable hypertext placed on top to provide a title and a description of the practical situation. It shows right under some image files related to the specific simulation, and at the bottom two button commands placed to move among the pages.

- $\quad$ Page 3 (figure $7 \mathrm{c}$ ) has a similar layout to page 2 apart from the image file that does not include a simulation but graphics and tables describing the mathematical laws related to the experiment. An editable hypertext is placed below to provide questions related to the simulation.

- $\quad$ Page 4 (figure 7d) is similar to page 1 and includes the final result of the experiment. This page formalizes the knowledge acquired in the previous pages through the formalization of physical laws.

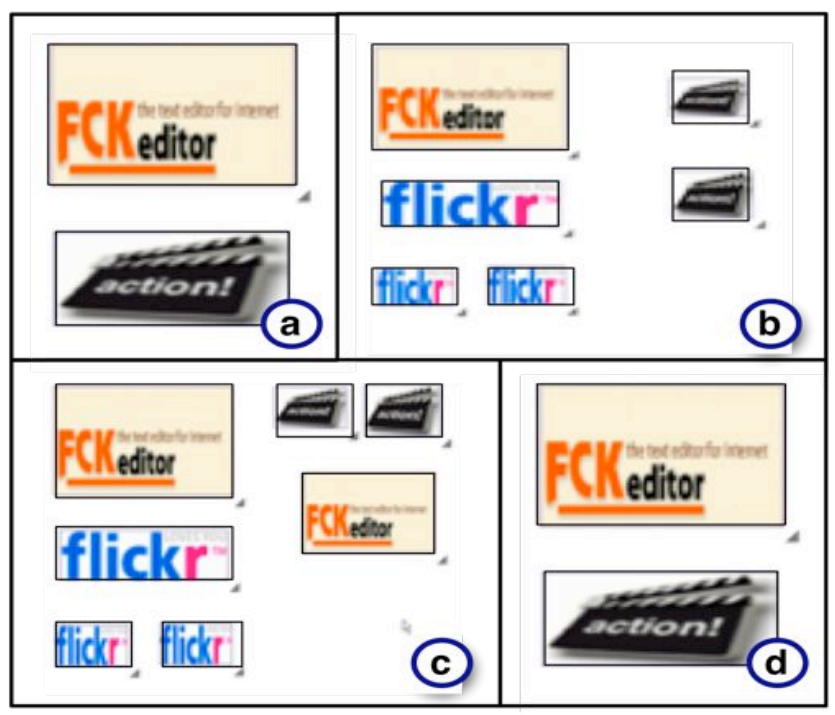

Figure 7. The four pages composing the VSE pedagogical template.
Working on the template developed, the teachers have developed three learning resources with the aim to explain the harmonic motion through a simple pendulum, the recursive algorithms through the Hanoi tower and permutations in combinatory calculus. As an example, some of the pages composing the learning resource about the pendulum motion are presented in figure 8 .

The learning resources developed have been then exported and uploaded on the e-learning system of the Faculty, together with further resources, to provide the students with support and additional material for classroom-based lessons.

Some students have been questioned about the on-line learning material and they commented that the template-based resources were particularly interesting since they had the possibility to experiment and reinforce theoretical concepts already learnt in the classroom activity playing with available experiments. Also, the teachers showed themselves enthusiastic that they were able to build quickly and easily (with no additional technical skills) engaging interactive learning resources.

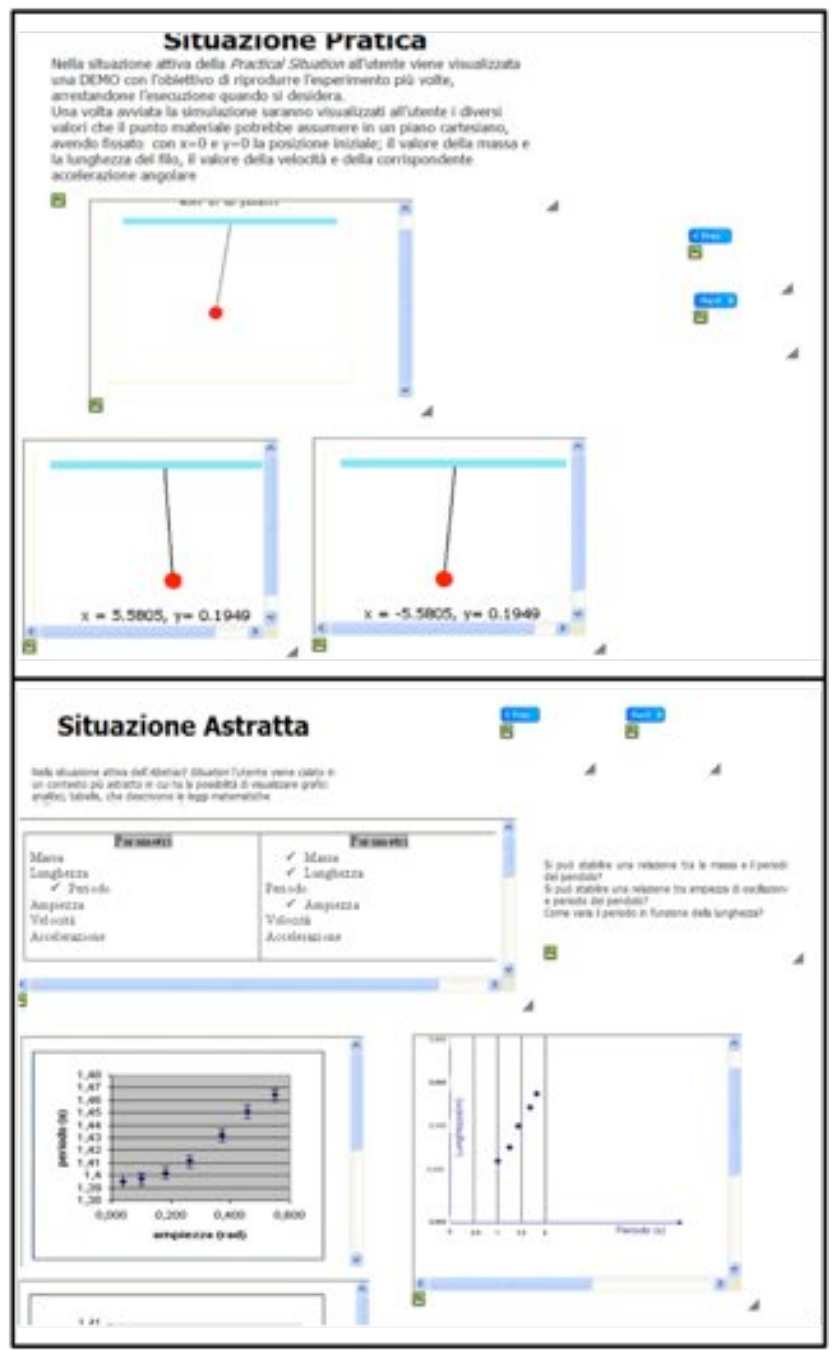

Figure 8. The four pages composing a learning resource about the pendulum motion basing on the VSE template. 


\section{CONCLUSIONS AND FUTURE WORK}

In this paper we proposed (and compared with similar initiatives available in the literature) pedagogical templates: an innovative methodology, inspired by design patterns and aimed at the definition of learning resources through the aggregation of atomic learning entities basing on pre-defined schemas.

In order to experiment the new methodology in a real setting, we developed (and presented in this paper) a Web-based authoring tool, inspired by mashing-up principles, allowing the teachers to build learning resources based on pedagogical templates by combining local learning entities with further entities coming from external sources. The developed authoring tool was then compared with similar tools coming from e-learning and Web 2.0 fields.

In order to validate both the approach and the developed prototype we experimented the latter inside an University course through the definition of a complex pedagogical template for Virtual Scientific Experiments and the building and the deploy of learning resources applying the template.

From interviews made with teachers, our authoring tool was found easy to be used without any need for specific competencies to quickly build learning resources basing on (pre-defined or ad-hoc) templates. On the contrary, several third-party authoring tools for e-learning entail a fairly steep learning curve to provide similar results. Students as well found learning resources made with our authoring tool particularly engaging.

These first results encourage us to continue the work to improve the methodology and the prototype integrating it in IWT [20], the learning system currently adopted by the Faculty of Engineering of the University of Salerno. After that a more rigorous and quantitative experimentation will be made whose results will be presented in a future paper.

\section{ACKNOWLEDGMENTS}

This work was partially financed by the Campania Region for the NewGenLearn (New Generation Learning) project, purposed to investigate new methodologies and technologies for the authoring and aggregation of advanced content for e-learning.

\section{REFERENCES}

[1] G. Trentin. Un Approccio Multidimensionale alla Sostenibilità dell'e-Learning. TD Tecnologie Didattiche n. 40, pp.14-20, 2006.

[2] A. Bain, R. Parkes. Curriculum Authoring Tools and Inclusive Classroom Teaching Practice: A Longitudinal Study. The British Journal of Educational Technology, 37(2), 177-190, 2006.

[3] H. Halff, P. Hsieh, B. Wenzel, T. Chudanov, M. Dirnberger, E. Gibson, C. Redfield. Requiem for a Development System: Reflections on Knowledge-Based, Generative Instruction. T.
Murray, S. Blessing, S. Ainsworth (Eds.). Authoring Tools for Advanced Technology Learning Environments. Kluwer Academic Publishers, 2003.

[4] M. Merrill. Using Knowledge Objects to Design Instructional Learning Environments. T. Murray, S. Blessing, S Ainsworth (Eds.). Authoring Tools for Advanced Technology Learning Environments. Kluwer Academic Publishers, 2003.

[5] E. Gamma, R. Helm, R. Johnson, J. M. Vlissides. Design Patterns: Elements of Reusable Object-Oriented Software. Addison-Wesley Professional, 1994.

[6] L. Anderson, D. Krathwohl. Taxonomy for Learning, Teaching and Assessing: A Revision of Bloom's Taxonomy of Educational Objectives. Longman, 2001.

[7] C. Alexander, S. Ishikawa, M. Silverstein. A Pattern Language. Oxford, UK: Oxford University Press, 1977.

[8] P. Avgeriou, A. Papasalouros, S. Retalis, M. Skordalakis. Towards a Pattern Language for Learning Management Systems. Educational Technology \& Society, 6(2), pp. 11-24, 2003.

[9] J. Bergin. Fourteen Pedagogical Patterns. http://www.pedagogicalpatterns.org/, 2003.

[10] M. Jara, F. Mohamad. Pedagogical templates for e-learning. Institute of Education, University of London, 2007.

[11] L. Gooyear. Educational design and networked learning: Patterns, pattern languages and design practice. Australasian Journal of Educational Technology, vol 21, pp. 82-101, 2005

[12] The Pedagogical Pattern Project. http://www.pedagogicalpatterns.org/.

[13] eXe Lerning Project Home (on SourceForge). $\mathrm{http} / / /$ sourceforge.net/projects/exe.

[14] Rapidly Create Online Courses (on the Microsoft Web Site). $\mathrm{http} / / /$ www.microsoft.com/learning/en/us/training/lcds.aspx.

[15] The Programmable Web FAQ (quoted on Wikipedia). http://www.programmableweb.com/faq.

[16] Microsoft Popfly Web Site. http://www.popfly.com/.

[17] Mozilla Ubiquity Project Home (on Mozilla Labs). http://labs.mozilla.com/projects/ubiquity/.

[18] Yahoo Pipes Web Site. http://pipes.yahoo.com/.

[19] A. Pierri, T. Tiropanis, I. Christou, S. Tsekeridou, B. Vassidialis. Application of a Virtual Scientific Experiment Model in Different Educational Contexts. In P. Cunningham, M. Cunningham (Eds.) Exploiting the Knowledge Economy: Issues, Applications, Case Studies, IOS Press, 2006.

[20] N. Capuano, M. Gaeta, A. Micarelli. IWT: Una Piattaforma Innovativa per la Didattica Intelligente su Web. AI*IA Notizie, XVI, no. 1, p. 57-61, 2003. 